\title{
THE MODIFYING ROLE OF TOXIC SUBSTANCES ON GENOTOXIC EFFECT IN THE BODY DURING COMBINED ADMINISTRATION WITH CARCINOGEN (BENZO[A]PYRENE)
}

DOI: 10.36740/WLek202103209

\author{
Olga M. Ostash', Liudmyla E. Grygorenko' ${ }^{1}$, oksana V. Shvager², Svetlana V. Stepanchuk', Nina V. Balenko', \\ Igor 0. Chernychenko ${ }^{1}$ \\ 'STATE INSTITUTION “O.M. MARZEYEV INSTITUTE FOR PUBLIC HEALTH OF THE NATIONAL ACADEMY OF MEDICAL SCIENCES OF UKRAINE”, KYIV, UKRAINE \\ 2BOGOMOLETS NATIONAL MEDICAL UNIVERSITY, KYIV, UKRAINE
}

\begin{abstract}
The aim: of this work was to experimentally study the modifying role of toxic substances (phenol) in the manifestation of genotoxic and immunological changes in the body when exposed to a carcinogen (benzo[a]pyrene).

Materials and methods: Investigations were carried out in the chronic experiment on white random-bred male mice. Genotoxic (micronucleus test), immunologic and pathomorphological methods were used.

Results: As a result of the experiment on white outbred mice during the isolated peroral administration of benzo[a]pyrene (a single dose of $0.1 \mathrm{mg}$ ) and in combination with phenol (single doses of $0.1 \mathrm{mg} ; 0.002 \mathrm{mg}$ ) a carcinogenic effect (forestomach papillomas) has been established as well as general patterns of the manifestation of genotoxic and immunological changes regarding carcinogenesis and their dependence on the dose and duration of the administration of the substances in the early stages of the experiment. The established patterns involved parallelism of development and unidirectionality of the genotoxic effect (increasing of micronucleus incidence) and suppression of the T-cell immunity by the end of the month as well as reliable negative correlation between them.

Conclusions: It has been established that phenol has a modifying effect on carcinogenesis, which was shown as an increase in the micronuclei frequency, intensification of immunosuppression in the early stages and an increase in the multiplicity factor of the development of forestomach tumors.
\end{abstract}

KEY WORDS: micronuclear test, immunosuppression, carcinogenesis, phenol

Wiad Lek. 2021;74(3 p.II):613-618

\section{INTRODUCTION}

People nowadays are constantly affected by a complex of numerous chemical compounds of different types, which are characterized by a wide range of biological effects - from toxic to mutagenic and carcinogenic ones. According to the US National Toxicology Program, the total number of chemicals that a person is exposed to in the home, in the workplace or from an environmental source exceeds 100,000 , of which $5-10 \%$ are carcinogenic compounds and the same number accounts for mutagenic ones [1].

One of the adverse impacts of chemical pollution on human health is the increase in the number of cancer cases. Today it has been proven that the development of malignant tumors is determined not only by the initiating action of carcinogenic agents, but also by the modifying effect of accompanying toxic compounds [2-4].

In these circumstances, the problem of early detection and evaluation of hazardous chemicals and their complexes in order to develop and implement appropriate preventive measures requires accelerated testing methods.

\section{THE AIM}

The aim of this work was to experimentally study the role of toxic substances (phenol) in modifying the manifestation of genotoxic and immunological changes in the organism in the early stages of carcinogenic action (benzo[a]pyrene).

The choice of indicators was based on modern views on carcinogenesis, according to which the realization of the carcinogenic effect is possible providing that apart from mutation there will be additional disorders in the body, particularly immunosuppression [5-7].

In addition, it is commonly known that a mutagenic effect does not always mean the presence of carcinogenic properties.

\section{MATERIALS AND METHODS}

For the purpose of this study, a chronic experiment was conducted on 290 white outbred mice from the animal facility of JSC "Phoenix", Kyiv. Benzo[a]pyrene (BaP) (company: Sigma- Aldrich, USA and well-known modifier of carcinogenesis - phenol (Ph) (company:Lach - Ner, Czech Republic) were used in the study. 
The studies were conducted under conditions of isolated and combined peroral administration of these substances.

The animals were divided into 6 groups. Three groups of the mice were administered with the same single dose of $\mathrm{BaP}(0.1 \mathrm{mg})$ in triethylene glycol (TEG) separately (group 1) or in combination with phenol at single doses of $0.1 \mathrm{mg}$ (group 3) and $0.002 \mathrm{mg}$ (group 4). One group (group 2) was given only an aqueous solution of phenol at a dose of $0.1 \mathrm{mg}$. Two groups of the mice were control ones: solvent control (group 5, were given TEG at a dose of $0.2 \mathrm{ml}$ ) and intact (group 6). The substances were administered intragastrically through a probe, once a week at a dose of $0.2 \mathrm{ml}$.

6-7 mice from each group were sacrificed on different days - on days 9, 31, 95 from the beginning of the substance administration and during the developing of forestomach tumors (on days $182,332,423$ ) and biomaterials were taken for the further research. The work with the animals was performed in accordance with the rules of local Committee for Bioethics. Genotoxicity was studied using the micronucleus $(\mathrm{MN})$ test, taking into account its advantages over other genotoxic methods $[1,8]$.

Considering mainly a local nature of the carcinogenic effect of $\mathrm{BaP}$ and the convergence of organospecificity of the mutagenic effect according to the MN test and carcinogenetic one, only the target organ forestomach was taken for the study [1], which, flattened on thick paper, was fixed in $10 \%$ neutral buffered formalin. Half of a forestomach was used for the MN study, the rest -for the parallel study of pathomorphological changes. In this case, the pieces of a forestomach were treated according to the established techniques used in histopathology with creation of paraffin blocks. Histological sections were stained with hematoxylin and eosin.

At the same time, blood was collected for the immunotoxicity study, following the recommendations of WHO [9] and the Ministry of Health of Ukraine [10]. In this research the quantitative and qualitative composition of peripheral blood leukocytes, the number of killer cells, $\mathrm{T}$ and $\mathrm{B}$ lymphocytes, the spreading response of macrophages and polyethylene glycol 6000 precipitation of the circulating immune complex (CIC) were studied [11]. As a tissue antigen, forestomach and liver were used [11].

Cytogenetic effects were studied by using suspensions, which were prepared according to the recommendations [12]. The number of MN was counted per 1000 epithelial cells of each mouse's forestomach using Primo Star (ZEISS) and BIOLAM microscopes at 1000 and 900 magnification respectively using immersion lenses. MN detection was performed with the use of encoded medication, according to the criteria given in the cited literature [1].

The findings were evaluated with statistical methods traditionally used in biomedical research and Student's t-test. The relationship between the MN frequency and immunosuppression was determined using the Pearson correlation coefficient [13].

\section{RESULTS}

The results of the study of genotoxicity in mouse forestomach epithelium on different days from the beginning of peroral administration of $\mathrm{BaP}$ and its combinations with phenol are illustrated in table I.

As can be seen from the data given, during isolated administration (group 1) BaP caused a genotoxic effect at each stage of the study (days 9, 31, 95 after injections 2, 5,11 respectively), characterized by a significantly higher micronuclei frequency compared to that found in the control group. (groups 2, 5, and 6).

Second, the genotoxic effect increased with an increase in the frequency of the administration of the carcinogen. Thus, the number of micronucleated cells increased by a factor of 2.05 and 1.7 on days 31 and 95 after injections 5 and 11 respectively, compared to the same parameters on day 9 after 2 injections.

At the same time, regarding the dynamics of the genotoxic effect (Table II), it showed a decrease $(p>0.05)$ in the micronuclei frequency on day 95 compared to day 31 , despite the continuous administration of the carcinogen.

This phenomenon supposedly indicates that the growth of cytogenetic effect during prolonged exposure to carcinogen occurs only within the values of a certain range, after which the further growth of the effect comes to a stop. This is obviously due to the fact that some doses of carcinogens are able to induce a certain micronuclei frequency, which is completely consistent with the experimental data and human observations as for the dependence of genotoxic effects on the dose of mutagenic carcinogens.

Similar dose-effect and time patterns of genotoxicity were also found during combined exposure to BaP simultaneously with phenol (Tables I, II).

However, in this case, phenol tends to increase the genotoxic effect ( $p>0.05)$, which depends on its dose in the complex. At the same time, with the exposure to phenol at a dose of $0.1 \mathrm{mg}$ (group 3), an increase in the micronuclei frequency was noticed as early as on day 9 , whereas when exposed to a lower dose of phenol $(0.002 \mathrm{mg})$ in combination (group 4), an increase was noticed later, on day 31 and 95 of the experiment and quantitative changes were more pronounced.

Unlike BaP, phenol (group 2) and TEG (group 5) did not cause genotoxic changes when administered separately.

Studies conducted at a later date of the experiment, months 6, 11, 14 after the beginning of peroral administration of the substances, revealed a new substantial increase in the micronuclei frequency in the animals which were given the carcinogen alone or in combination with phenol. However, in this case, the increase in the number of micronucleated cells was less related to the total dose of $\mathrm{BaP}$ and the modifying effect of phenol, and more to the nature of morphological changes in the forestomach. Thus, in the presence of pre-tumor changes - diffuse and focal hyperplasia of the forestomach epithelium, the micronuclei frequency in some mice was 6-7 per 1000 cells analyzed. For the mice with visually detected and histologically confirmed diagnose of forestomach papillomas, accompanied by diffuse and focal epithelial hyperplasia, this index reached 12-16 cells per 1000 analyzed. At the same time, there was an increase in the number of multinucleated cells, 
Table I. MN frequency (\%) in the forestomach of white outbred mice after peroral intragastric administration of benzo[a]pyrene separately and in combination with phenol on different days of the experiment

\begin{tabular}{|c|c|c|c|c|c|}
\hline \multirow{2}{*}{ Group } & \multirow{2}{*}{ Substances } & \multirow{2}{*}{$\begin{array}{l}\text { Single dose, } \\
\text { mg, ml }\end{array}$} & \multicolumn{3}{|c|}{ MN frequency } \\
\hline & & & day 9 & day 31 & day 95 \\
\hline 1 & $\mathrm{BaP}$ & 0.1 & $1.33 \pm 0.21 *$ & $2.83 \pm 0.31^{*}$ & $2.33 \pm 0.33^{*}$ \\
\hline 2 & Phenol & 0.1 & $0.33 \pm 0.21$ & $0.50 \pm 0.22$ & $0.33 \pm 0.21$ \\
\hline 3 & $\mathrm{BaP}+\mathrm{Ph}$ & $0.1+0.1$ & $1.67 \pm 0.21^{*}$ & $3.17 \pm 0.40^{*}$ & $2.83 \pm 0.31^{*}$ \\
\hline 4 & $\mathrm{BaP}+\mathrm{Ph}$ & $0.1+0.002$ & $1.33 \pm 0.21^{*}$ & $3.50 \pm 0.22^{*}$ & $3.00 \pm 0.26^{*}$ \\
\hline 5 & TEG & 0.2 & $0.50 \pm 0.022$ & $0.50 \pm 0.022$ & $0.67 \pm 0.21$ \\
\hline 6 & control & & $0.33 \pm 0.21$ & $0.33 \pm 0.21$ & $0.50 \pm 0.22$ \\
\hline
\end{tabular}

Notes: * - the difference is significant within the intact control: day $9(\mathrm{P}<0.01) ; 31,95$ day $(\mathrm{P}<0.001)$

Table II. Dynamics of the change in MN frequency (\%)in the forestomach of white outbred mice after peroral intragastric administration of benzo (a) pyrene separately and in combination with phenol on different days of the experiment

\begin{tabular}{|c|c|c|c|c|c|c|c|c|c|}
\hline \multirow{4}{*}{$\begin{array}{l}\text { Compared terms } \\
\text { of the experiment. } \\
\text { days (number of } \\
\text { applications) }\end{array}$} & \multicolumn{9}{|c|}{ Substances. single doses. mg } \\
\hline & \multicolumn{3}{|c|}{ BP 0.1} & \multicolumn{3}{|c|}{ BP $0.1+P h 0.1$} & \multicolumn{3}{|c|}{ BP $0.1+$ Ph 0.002} \\
\hline & \multicolumn{3}{|c|}{ Statistical parameters } & \multicolumn{3}{|c|}{ Statistical parameters } & \multicolumn{3}{|c|}{ Statistical parameters } \\
\hline & $M \pm m$ & $\mathbf{t}$ & $\mathbf{p}$ & $M \pm m$ & $\mathbf{t}$ & $\mathbf{p}$ & $M \pm m$ & $\mathbf{t}$ & $\mathbf{p}$ \\
\hline $9(2)$ & $1.33 \pm 0.21$ & & & $1.67 \pm 0.21$ & & & $1.33 \pm 0.21$ & & \\
\hline $31(5)$ & $2.83 \pm 0.31$ & 4.07 & $<0.01$ & $3.17 \pm 0.40$ & 3.32 & $<0.01$ & $3.50 \pm 0.22$ & 7.13 & $<0.001$ \\
\hline $9(2)$ & $1.33 \pm 0.21$ & & & $1.67 \pm 0.21$ & & & $1.33 \pm 0.21$ & & \\
\hline $95(12)$ & $2.33 \pm 0.33$ & 2.57 & $<0.01$ & $2.83 \pm 0.31$ & 3.09 & $<0.01$ & $3.00 \pm 0.26$ & 4.99 & $<0.001$ \\
\hline $31(5)$ & $2.83 \pm 0.30$ & & & $3.17 \pm 0.40$ & & & $3.50 \pm 0.22$ & & \\
\hline $95(12)$ & $2.33 \pm 0.33$ & 1.86 & $>0.05$ & $2.83 \pm 0.31$ & 0.67 & $>0.05$ & $3.00 \pm 0.26$ & 1.47 & $>0.05$ \\
\hline
\end{tabular}

up to 34-37 per 1000 cells, mainly 2-nucleus, sometimes with $2-4$ nuclei, as well as nuclei with protrusions-tailed.

The parallel study of immunological responses also showed different response of the animal body to the separate and combined administration of the carcinogen and toxic substances as to quantitative and qualitative composition of the indexes. The latter depending on the dose and duration of administration included components of the body's nonspecific defense, cellular and humoral immunity, allergy symptoms.

Thus, isolated administration of $\mathrm{BaP}$ (group 1) on days 9 and 31 did not cause any significant deviations in hematological and immunological parameters compared to those in the control group (group 6) (Table III).

At the same time, chemical carcinogens had a usual suppressive effect on the immune system, which was showed by a significant $(\mathrm{p}<0.05)$ decrease in the relative number of T-lymphocytes compared to the control and indicated the suppression of the cellular immunity, although the total number of T-lymphocytes as well as B-cell population did not change significantly.

With continued exposure to $\mathrm{BaP}$ up to 3 months no great difference in hematological parameters compared to the control group was found (Table IV).

At the same time, immunosuppression was intensified, which was shown by the suppression of both cellular and humoral immunity, with a significant $(\mathrm{p}<0.05)$ decrease in the relative and absolute numbers of $\mathrm{T}$ and $\mathrm{B}$ lymphocytes.
Additional administration of phenol on day 9 did not cause any serious immunological changes compared with the isolated effect of $\mathrm{BaP}$. Meanwhile, with the increase in the duration of phenol intake (on day 31), suppression of the immune system considerably strengthened. This was manifested by the fact that in addition to the suppression of the $\mathrm{T}$ component of the immune system (significantly lower $(\mathrm{p}<0.05)$ percentage of $\mathrm{T}$ lymphocytes than in the control group), inhibition of the body's nonspecific defense was also observed: significant $(\mathrm{p}<0.05)$ decrease in the relative number of segmented neutrophils (SNF) was found in the animals of both groups 3 and 4 compared to the control, and the total number of neutrophils decreased when exposed to the combination of $\mathrm{BaP}$ with a higher dose of toxicant (group 3).

As further studies confirmed, the latter was caused by the toxicity of phenol. Thus, the isolated administration of phenol (group 2) on day 9 (Table III) did not cause any serious immunological changes. However, the inhibition of nonspecific protective factors of an organism was found on day 31 , which was shown as a significant $(\mathrm{p}<0.05)$ decrease compared to the control regarding the relative number of neutrophils, including segmented neutrophils (SNF), and phagocytic activity of neutrophilic granulocytes. The other hematological indices did not differ considerably from the control values. At the same time, there was also cellular immunity suppression, as evidenced by the significantly 
Table III. Immunological parameters of the mice on the 31st day of peroral administration of benzo[a]pyrene and phenol, separately and in combination

\begin{tabular}{|c|c|c|c|c|c|c|c|}
\hline \multirow{2}{*}{\multicolumn{2}{|c|}{ Values }} & \multicolumn{6}{|c|}{ Experimental groups of animals } \\
\hline & & group 1 & group 2 & group 3 & group 4 & group 5 & group 6 \\
\hline \multicolumn{2}{|c|}{ Leukocytes, $\times 10^{9} / л$} & $17.38 \pm 1.52$ & $17.08 \pm 1.39$ & $17.97 \pm 2.24$ & $19.63 \pm 0.77$ & $15.28 \pm 1.13$ & $18.67 \pm 2.41$ \\
\hline \multicolumn{2}{|c|}{ Natural killers,\% } & $0.83 \pm 0.17$ & $0.67 \pm 0.21$ & $0.67 \pm 0.21$ & $0.67 \pm 0.21$ & $0.67 \pm 0.21$ & $1.17 \pm 0.17$ \\
\hline \multicolumn{2}{|c|}{ Band neutrophils. $\%$} & $4.17 \pm 0.31^{*}$ & $3.33 \pm 0.42$ & $3.00 \pm 0.45$ & $3.67 \pm 0.67$ & $3.00 \pm 0.37$ & $2.83 \pm 0.31$ \\
\hline \multicolumn{2}{|c|}{ Segmented neutrophils, \% } & $19.50 \pm 0.81$ & $17.50 \pm 0.72 *$ & $17.17 \pm 0.75^{*}$ & $16.67 \pm 1.45^{*}$ & $16.17 \pm 0.79 *$ & $21.00 \pm 0.82$ \\
\hline \multicolumn{2}{|c|}{ Eosinophils, \% } & $3.00 \pm 0.63$ & $4.00 \pm 0.77$ & $4.83 \pm 0.48$ & $4.17 \pm 0.48$ & $4.50 \pm 0.85$ & $3.17 \pm 0.48$ \\
\hline \multicolumn{2}{|c|}{ Monocytes, \% } & $1.00 \pm 0.00$ & $1.00 \pm 0.00$ & $1.00 \pm 0.00$ & $1.00 \pm 0.00$ & $1.00 \pm 0.00$ & $1.00 \pm 0.00$ \\
\hline \multicolumn{2}{|c|}{ Lymphocytes, \% } & $71.50 \pm 1.12$ & $73.50 \pm 1.06$ & $73.33 \pm 0.80$ & $73.83 \pm 1.47$ & $74.67 \pm 1.17^{*}$ & $70.83 \pm 0.87$ \\
\hline \multicolumn{2}{|c|}{ Lymphocytes, $\times 10^{9} / \mathrm{I}$} & $12.48 \pm 1.20$ & $12.54 \pm 0.99$ & $13.19 \pm 1.69$ & $14.51 \pm 0.70$ & $11.36 \pm 0.72$ & $13.30 \pm 1.84$ \\
\hline \multicolumn{2}{|c|}{ Neutrophils, \% } & $23.67 \pm 0.88$ & $20.83 \pm 0.87^{*}$ & $20.17 \pm 1.01^{*}$ & $20.33 \pm 1.52$ & $19.17 \pm 0.70^{*}$ & $23.83 \pm 0.83$ \\
\hline \multicolumn{2}{|c|}{ Neutrophils, $\times 10^{9} / 1$} & $4.06 \pm 0.29$ & $3.52 \pm 0.23$ & $3.62 \pm 0.48$ & $3.96 \pm 0.26$ & $2.95 \pm 0.28$ & $4.39 \pm 0.49$ \\
\hline \multicolumn{2}{|c|}{ T-lymphocytes, \% } & $17.83 \pm 0.70^{*}$ & $19.67 \pm 1.05^{*}$ & $19.33 \pm 0.67^{*}$ & $24.00 \pm 0.89 *$ & $27.50+0.89$ & $30.00 \pm 0.55$ \\
\hline \multicolumn{2}{|c|}{ T-lymphocytes, $\times 10^{9} / \mathrm{l}$} & $2.23 \pm 0.23$ & $2.49 \pm 0.29$ & $2.52 \pm 0.30$ & $2.87 \pm 0.22$ & $3.10 \pm 0.15$ & $3.85 \pm 0.68$ \\
\hline \multicolumn{2}{|c|}{ B-lymphocytes, \% } & $24.33 \pm 0.42$ & $32.00 \pm 1.29 *$ & $33.67 \pm 0.99 *$ & $32.33 \pm 0.88^{*}$ & $30.17 \pm 0.79 *$ & $25.50 \pm 0.92$ \\
\hline \multicolumn{2}{|c|}{ B-lymphocytes, $\times 10^{9} / \mathrm{I}$} & $3.04 \pm 0.30$ & $4.02 \pm 0.38$ & $4.36 \pm 0.46$ & $4.69 \pm 0.26$ & $3.44 \pm 0.28$ & $3.46 \pm 0.57$ \\
\hline \multirow{2}{*}{$\begin{array}{c}\text { Number of } \\
\text { phagocytising cells }\end{array}$} & $\%$ & $81.83 \pm 3.26$ & $81.83 \pm 2.01^{*}$ & $88.83 \pm 2.15$ & $85.50 \pm 2.55$ & $88.83 \pm 3.15$ & $90.33 \pm 2.39$ \\
\hline & $\times 10^{9} / I$ & $3.28 \pm 0.17$ & $2.86 \pm 0.15$ & $3.20 \pm 0.40$ & $3.37 \pm 0.20$ & $2.65 \pm 0.34$ & $3.97 \pm 0.48$ \\
\hline
\end{tabular}

Note. * - Significant differences compared to control group $6(p<0.05)$

( $\mathrm{p}<0.05)$ lower percentage of $\mathrm{T}$ lymphocytes compared to the intact mice. On the contrary, the percentage of $\mathrm{B}$-lymphocytes increased, which indicated the activation of the humoral immunity. At the end of month 3, there was a recovery of T- and B-lymphocytes as well as the other parameters with further approaching the control values.

\section{DISCUSSION}

Thus, the findings indicate that the earliest sensitive immunological indicator of the body's response to the exposure to $\mathrm{BaP}$ and its combinations with phenol is the T-cell component of the immunity, whose changes according to the type of suppression corresponded to carcinogenesis and were found as early as on day 31 . At a later date, on day 95, the suppression of the T-cell component was accompanied by the suppression of the humoral immunity against the background of lymphocytopenia, leukopenia, when exposed to combination with phenol.

During the pathomorphological study, the development of pre-tumor changes and forestomach tumors was found only in the mice which were given $\mathrm{BaP}$ or $\mathrm{BaP}$ in combination with phenol, which confirms carcinogenicity of the experimental dose of the carcinogen for all ways of administration. Pre-tumor changes were diffuse and focal hyperplasia of the forestomach mucosa (carcinogenesis stages I, II by L.M. Shabad), tumors were papillomas and were first found in a few cases 6 months later after the beginning of the administration [14]. 14 months later, the same $100 \%$ tumor development was observed after both isolated administration of $\mathrm{BaP}$ and in combination with the toxicant.
However, after adding phenol to the carcinogen (combined effect), a dose-dependent increase in the multiplicity factor (M) of forestomach papillomas was observed, which is considered as one of the indicators of carcinogenic activity in the early stages of tumor development. During the administration of $\mathrm{BaP}$ in combination with phenol at doses of $0.1 \mathrm{mg} ; 0.002 \mathrm{mg}$ it was 5.0 and 3.2 respectively, compared to 1.8 when exposed to $\mathrm{BaP}$ alone. This indicates that phenol triggers carcinogenesis at the stage when forestomach tumors occur. It should be noted that the modifying effect of the toxicant coincides with its action in the early period, which was shown as a tendency towards intensification of the genotoxic effect and immunosuppression through additional suppression of the components of the body's nonspecific defense, lymphocytopenia, leukopenia.

When comparing the dynamics of cytogenetic and immunotoxic changes, it was found that the increase in the micronuclei frequency during the first month of the experiment occurred in parallel with the decrease in the number of T-lymphocytes, i.e. with the development of immunosuppression. These patterns occurred during both isolated administration of $\mathrm{BaP}$, and in combination with phenol.

To sum up, the studies have shown parallelism of development and unidirectionality of changes in mutagenicity and immunotoxicity indicators as to carcinogenesis, the presence of a reliable correlation between them, and convergence with the final effect - the development of tumors. However, the intensity of carcinogenesis both in the early stage (genotoxic, immunological changes) and later (development of pre-tumor morphological changes and tumors) increases when exposed to the carcinogen together with accompanying modifiers - toxic substances. 
Table IV. Immunological parameters of the mice on the 95th day of peroral administration of benzo[a]pyrene and phenol, separately and in combination

\begin{tabular}{|c|c|c|c|c|c|c|c|}
\hline \multirow{2}{*}{\multicolumn{2}{|c|}{ Values }} & \multicolumn{6}{|c|}{ Experimental groups of animals } \\
\hline & & group 1 & group 2 & group 3 & group 4 & group 5 & group 6 \\
\hline \multicolumn{2}{|c|}{ Leukocytes, $\times 10^{9} / л$} & $13.22 \pm 1.08$ & $12.98 \pm 1.61$ & $15.02 \pm 0.51$ & $* 12.83 \pm 0.90$ & $15.90 \pm 1.15$ & $17.55 \pm 1.61$ \\
\hline \multicolumn{2}{|c|}{ Natural killers, $\%$} & $0.67 \pm 0.21$ & $0.50 \pm 0.22$ & $0.67 \pm 0.21$ & $0.67 \pm 0.21$ & $1.00 \pm 0.26$ & $0.50 \pm 0.22$ \\
\hline \multicolumn{2}{|c|}{ Band neutrophils. \% } & $3.50 \pm 0.34$ & $3.33 \pm 0.33$ & $4.00 \pm 0.45$ & $4.00 \pm 0.37$ & $3.67 \pm 0.21$ & $4.33 \pm 0.49$ \\
\hline \multicolumn{2}{|c|}{ Segmented neutrophils, \% } & $18.00 \pm 0.63$ & $21.00 \pm 1.51$ & $18.50 \pm 0.89$ & *21.67 \pm 0.89 & $* 18.00 \pm 1.06$ & $16.00 \pm 1.51$ \\
\hline \multicolumn{2}{|c|}{ Eosinophils, $\%$} & $3.50 \pm 0.56$ & $5.00 \pm 0.63$ & $4.50 \pm 0.56$ & $4.17 \pm 0.60$ & $4.17 \pm 0.48$ & $5.00 \pm 0.68$ \\
\hline \multicolumn{2}{|c|}{ Lymphocytes, \% } & $73.33 \pm 1.15$ & $69.17 \pm 1.70$ & $71.36 \pm 1.15$ & 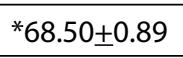 & $72.17 \pm 1.51$ & $73.17 \pm 1.17$ \\
\hline \multicolumn{2}{|c|}{ Lymphocytes, $\times 10^{9} / \mathrm{I}$} & $9.72 \pm 0.89$ & $9.07 \pm 1.27$ & $10.71 \pm 0.39$ & ${ }^{*} 8.75 \pm 0.53$ & $11.47 \pm 0.86$ & $12.87 \pm 1.24$ \\
\hline \multicolumn{2}{|c|}{ Neutrophils, $\%$} & $21.50 \pm 0.85$ & $24.33 \pm 1.33$ & $22.50 \pm 0.99$ & $* 25.67 \pm 0.84$ & $* 21.67 \pm 1.20$ & $20.33 \pm 1.31$ \\
\hline \multicolumn{2}{|c|}{ Neutrophils, $\times 10^{9} / \mathrm{I}$} & $2.81 \pm 0.18$ & $3.09 \pm 0.30$ & $3.37 \pm 0.18$ & $3.32 \pm 0.31$ & $3.43 \pm 0.29$ & $3.50 \pm 0.24$ \\
\hline \multicolumn{2}{|c|}{ T-lymphocytes, \% } & *18.67 \pm 0.76 & $19.33 \pm 0.84$ & $20.83 \pm 0.31$ & ${ }^{*} 17.17 \pm 0.60$ & *14.67士0.56 & $21.83 \pm 0.91$ \\
\hline \multicolumn{2}{|c|}{ T-lymphocytes, $\times 10^{9} / \mathrm{I}$} & ${ }^{*} 1.81 \pm 0.17$ & $1.98 \pm 0.38$ & $2.23 \pm 0.08$ & ${ }^{*} 1.50 \pm 0.10$ & ${ }^{*} 1.68 \pm 0.15$ & $2.83 \pm 0.33$ \\
\hline \multicolumn{2}{|c|}{ B-lymphocytes, \% } & 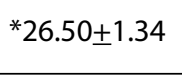 & $30.33 \pm 0.76$ & $28.83 \pm 1.19$ & $* 23.50 \pm 1.09$ & $* 25.83 \pm 1.25$ & $31.67 \pm 0.76$ \\
\hline \multicolumn{2}{|c|}{ B-lymphocytes, $\times 10^{9} / \mathrm{I}$} & $* 2.58 \pm 0.27$ & $2.74 \pm 0.37$ & $3.08 \pm 0.16$ & $* 2.05 \pm 0.14$ & $2.99 \pm 0.34$ & $3.09 \pm 0.45$ \\
\hline \multirow{2}{*}{$\begin{array}{c}\text { Number of } \\
\text { phagocytosing cells }\end{array}$} & $\%$ & $94.67 \pm 1.43$ & $94.17 \pm 1.49$ & $90.00 \pm 2.48$ & $92.50 \pm 1.59$ & $92.33 \pm 1.89$ & $93.17 \pm 1.01$ \\
\hline & $\times 10^{9} / 1$ & $2.66 \pm 0.19$ & $2.73 \pm 0.27$ & $3.06 \pm 0.22$ & $3.06 \pm 0.28$ & $3.18 \pm 0.31$ & $3.26 \pm 0.24$ \\
\hline
\end{tabular}

Note. * - Significant differences compared to control group $6(p<0.05)$

The importance of such a conclusion should be taken into account in the process of hygienic assessment of the state of the environment, which real impact on a person is connected with the simultaneous intake of carcinogenic and toxic compounds.

\section{CONCLUSIONS}

1. According to the findings of the parallel studies, a carcinogenic effect (development of forestomach tumors) and common patterns of the manifestation of genotoxic and immunological changes in the animals regarding carcinogenesis during isolated and combined administration of $\mathrm{BaP}$ and phenol and their dependence on the dose and duration of the exposure to the substances have been determined.

2. Carcinogenesis intensification by phenol has been established, which was shown by the increase in the micronuclei frequency and intensification of immunosuppression in the early stage as well as an increase in the multiplicity factor of the development of forestomach tumors (papillomas) at a later date compared to isolated $\mathrm{BaP}$ effects.

3. The results obtained indicate an oncological danger from combined administration of carcinogenic and toxic compounds, the formation of which begins in the early stages and manifests as a genotoxic effect in combination with immunosuppression, which must be taken into account during hygienic assessment of the state of the environment.

\section{REFERENCES}

1. Rakhmanin Yu.A. Poliorgannyy mikroyadernyy test v ekologogigienicheskih issledovaniyah [Multiorgan Micronucleus Test in the Ecological and Hygienic Studies]. Genius. 2007: 2-95. (In Russian).
2. Bogovski P. Modulators of experimental carcinogenesis. Ed. Turusov V.S., Montesano R. Lyon: JARC. 1983: 305.

3. Wilson H. K.., Buckeridge S.A.., Yau W. et al. Investigating the toxic effects of 2-aminoanthracene ingestion in pregnant Sprague Dawley dams. J Environ Sci Health B. 2018:4;53(5):283-289. doi: 10.1080/03601234.2017.1421837.

4. Sonoda J., SekiY., Hakura A. et al. Time course of the incidence/multiplicity and histopathological features of murine colonic dysplasia, adenoma and adenocarcinoma induced by benzo[a]pyrene and dextran sulfate sodium. J Toxical Pathol. 2016;29(1):74. doi: 10.1293/tox.2014-0061.

5. Wen H., Yuan L., Wei C. et al. Effects of combined exposure to formaldehyde and benzene on immune cells in the blood and spleen in Balb/c mice. Environ Toxicol Pharmacol. 2016;45:265-73.

6. Alegbeleye $0.0 . .$, Opeolu B.0.., JacksonV.A. Polycyclicaromatichydrocarbons: a critical review of environmental occurrence and bioremediation. Environ Manage. 2017;60(4):758-783. doi: 10.1007/s00267-017-0896-2.

7. Kaur G., Pinkston R., Mclemore B. et al. Immunological and toxicological risk assessment of e-cigarettes. Eur Respir Rev. 2018;28:27(147):170119. doi: 10.1183/16000617.0119-2017.

8. Sycheva L., ZhurkovV., Rahmanin Yu. et-al. Novyiy podhod k diagnostike mutagennyih i kantserogennyih svoystv okrujayuschey sredyi [A new approach to the diagnosis of mutagenic and carcinogenic properties of the environment]. Hygiene and Sanitation. 2003;6:87-91. (In Russian).

9. Principles and methods for assessing direct immunotoxicity associated with exposure to chemicals. Geneva: WHO. 1996: 390.

10. Prodanchuk M.H., Zhminko P.H., Zinchenko D.V. Doslidzhennia imunotoksychnoi dii potentsiino nebezpechnykh khimichnykh rechovyn pry yikh hihiienichnyi rehlamentatsii: Metodychni rekomendatsii [The research of immunotoxic action of potentially dangerous substances during their hygienic regulation: Methodical recommendations]. Book of normative documents for health protection. Kyiv. 2003:149-168. (In Ukrainian). 
11. Oczenka vliyaniya faktorov okruzhayushhej sredy' na immunologicheskuyu reaktivnost' organizma: Metodicheskie rekomendaczii [Assessment of the influence of environmental factors on the immunological reactivity of the organism: Methodical recommendations]. Marzeev A. N. Research Institute of General and Communal Hygiene. Kyiv. 1988:3-23. (In Ukrainian).

12. Otsenka mutagennoy aktivnosti faktorov okrujayuschey sredyi $v$ kletkah raznyih organov mlekopitayuschih mikroyadernyim metodom: metodicheskie rekomendatsii [Evaluation of mutagenic activity of environmental factors in the cells of various organs of mammals with micronucleus method: the guidelines. methodological recommendations]. Interdepartmental Scientific Council for Human Ecology and Environmental Health of the Russian Federation. 2001: 22. (In Russian).

13. Peter J. Costa. Statistical pattern recognition and classification. Peter J. Costa. Applied mathematics for the analysis of biomedical data: models, methods, and MATLAB. In: John Wiley \& Sons. New Jersey: 2017: 93-141.

14. Shabad L.M. Predrak v eksperimentalno-morfologicheskom aspekte [The precancer in the experimental morphological aspect]. Moscow. 1967: 384. (In Russian).

This work was performed as part of research work and supported by government of Ukraine "Scientific substantiation of short-term tests for hygienic assessment of carcinogenic factors" (2008-2011, № 0107U010019).

\section{ORCID and contributionship:}

Olga M. Ostash: 0000-0002-5311-9908 A, B, C, D

Liudmyla E. Grygorenko: 0000-0001-5805-080X ${ }^{B, D}$

Oksana V. Shvager: 0000-0001-6070-872X ${ }^{B, C}$

Svetlana V. Stepanchuk: 0000-0003-1938-7463 ${ }^{\text {B, C }}$

Nina V. Balenko: 0000-0002-3871-7600 ${ }^{A, E}$

Igor O. Chernychenko: 0000-0002-4784-4628 ${ }^{F}$

\section{Conflict of interest:}

The Authors declare no conflict of interest.

\section{CORRESPONDING AUTHOR}

\section{Olga M. Ostash}

0.M. Marzeyev Institute for Public Health of the National Academy

of Medical Sciences of Ukraine

50 Popudrenko St., 02094 Kyiv, Ukraine

tel.: +38(068) 301-27-02

e-mail:olya.ostash@gmail.com

Received: 10.11 .2020

Accepted: 05.03 .2021

A - Work concept and design, B - Data collection and analysis, C - Responsibility for statistical analysis,

D-Writing the article, $\mathbf{E}$-Critical review, $\mathbf{F}$ - Final approval of the article 